\title{
Influence of Beta-1 Adrenergic Receptor Genotype on Cardiovascular Response to Exercise in Healthy Subjects
}

\author{
Eli F. Kelley ${ }^{\mathrm{a}, \mathrm{c}}$, Eric M. Snyder ${ }^{\mathrm{a}}$, Bruce D. Johnson ${ }^{\mathrm{b}}$
}

\begin{abstract}
Background: The beta-1 adrenergic receptor (ADRB1) has been shown to play a functional role in cardiomyocyte function and accounts for up to $80 \%$ of the cardiac tissue adrenergic receptors with ADRB1 stimulation increasing cardiac rate, contractility and work. Multiple polymorphisms of the $A D R B 1$ have been identified such as the Gly49 polymorphism that includes at least one glycine (Gly) for serine (Ser) at amino acid 49 resulting in either homozygous for Gly (Gly49Gly) or heterozygous for Gly (Gly49Ser) polymorphisms. Heart failure patients with this polymorphism (Gly49) have been shown to have improved cardiac function and decreased mortality risk, but if there is an effect in healthy subjects is less clear. The purpose of this study was to determine the effects of the Gly/Ser polymorphism at position 49 of the $A D R B I$ on the cardiovascular response to exercise in healthy subjects.
\end{abstract}

Methods: We performed genotyping of the ADRB1 (amino acid 49) and high-intensity, steady-state exercise on 71 healthy subjects $($ Ser49Ser $=52$, Gly49Ser $=19)$.

Results: There were no differences between genotype groups in age, height, weight, body mass index (BMI), or watts achieved (age $=28.9$ \pm 5.6 years (yrs.), $30.6 \pm 6.4$ yrs., height $=173.6 \pm 9.9 \mathrm{~cm}, 174 \pm 7.5$ $\mathrm{cm}$, weight $=74.4 \pm 13.3 \mathrm{~kg}, 71.9 \pm 13.5 \mathrm{~kg}, \mathrm{BMI}=24.6 \pm 3.5,23.6 \pm$ 3.3 , and watts $=223.8 \pm 76.8,205 \pm 49.4$, for Ser49Ser and Gly49Ser respectively). Additionally, there were no differences for genotype groups for cardiac output (CO), systolic blood pressure $\left(\mathrm{BP}_{\text {sys }}\right)$, or diastolic blood pressure $\left(\mathrm{BP}_{\text {dias }}\right)$ at rest, maximal exercise, or in change from rest to maximal exercise. The genotype groups differed significantly in heart rate $\left(\mathrm{HR}_{\max }\right)$ at maximal exercise and cardiac index at rest $(\mathrm{CI})\left(\mathrm{HR}_{\max }=184.2 \pm 9.5 \mathrm{bpm}, 190.7 \pm 10.6 \mathrm{bpm}, \mathrm{CI}=0.063 \pm\right.$ $0.014,0.071 \pm 0.013$, for Ser49Ser and Gly49Ser respectively). There was a trend towards significance $(\mathrm{P}=0.058)$ for the change in stroke volume from rest to peak exercise $(\Delta \mathrm{SV})(0.016 \pm 0.018 \mathrm{~L}, 0.0076 \pm$ $0.012 \mathrm{~L}$, for Ser49Ser and Gly49Ser respectively).

Manuscript submitted October 1, 2018, accepted October 23, 2018

${ }^{a}$ Department of Kinesiology, University of Minnesota, Minneapolis, MN 55455 , USA

bDivision of Cardiovascular Diseases, Mayo Clinic, Rochester, MN 55905, USA

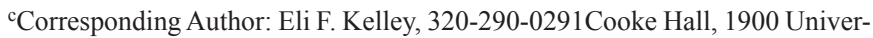
sity Avenue SE, Minneapolis, MN 55455, USA. Email: Kelle833@d.umn.edu

doi: https://doi.org/10.14740/cr785
Conclusions: These data suggest genetic variations of the ADRB1 may influence cardiovascular responses to exercise in healthy subjects.

Keywords: Exercise; $A D R B 1$ polymorphism; Cardiovascular; Beta-1 genotype; Healthy

\section{Introduction}

The $\beta$-adrenergic receptors ( $\beta$-ARs) are part of a family of membrane proteins known as g-protein coupled receptors where, upon binding of a catecholamine to the receptor, stimulates a conformational change in the $\beta$-AR that causes coupling with G-proteins. G-proteins consist of $\alpha, \beta$, and $\gamma$ subunits and $\beta$-AR coupling leads to the dissociation of the G-protein into active $\mathrm{G} \alpha$ and $\mathrm{G} \beta$ subunits to mediate downstream signaling [1]. Moreover, $\beta$-AR agonist binding results in a dissociation of the stimulatory $\mathrm{G} \alpha\left(\mathrm{G}_{\alpha \mathrm{s}}\right)$ protein [2]. $\mathrm{G}_{\alpha \mathrm{s}}$-bound guanine triphosphate (GTP) then phosphorylates the enzyme adenylyl cyclase (AC). Both AC and cAMP have the ability to regulate downstream mechanisms via multiple internal cell signaling pathways [3-7]. Conversely, $\beta$-AR antagonist binding causes a competitive inhibition against catecholamine and sympathetic nervous stimulation, thereby inhibiting the dissociation of $\mathrm{G}_{\mathrm{s}}$ proteins [8].

One subtype of the $\beta$-ARs is the beta- 1 adrenergic receptor (ADRB1). The ADRB1 subtype has been shown to play a functional role in cardiomyocyte function and accounts for approximately $70 \%$ of the cardiac tissue adrenergic receptors in the atria, $80 \%$ in the ventricles, and $95 \%$ in the sinoatrial (SA) node [9]. Research has demonstrated that ADRB1 stimulation increases cardiac rate, contractility and work $[10,11]$. Multiple polymorphisms of the $A D R B 1$ have been identified as including a glycine (Gly) for serine (Ser) at amino acid 49 resulting in either homozygous for Gly (Gly49Gly) or heterozygous for Gly (Gly49Ser) polymorphisms. The Gly49 polymorphism has been shown to have decreased receptor density, decreased cAMP accumulation, and a dampening response to the cardiostimulant effect of norepinephrine infusion $[12,13]$. Heart failure (HF) patients with this polymorphism (Gly49) have also been shown to have improved cardiac function and decreased mortality risk [14-16]. Furthermore, studies have demonstrated autoantibodies against ADRB1 are associated with more favorable myocardial recovery in patients with recent-onset 
cardiomyopathy [17]. This suggests the Gly49 polymorphism may have inherent cardioprotective effects similar to that of a beta-blocker.

While many studies have demonstrated the cardioprotective effect of the Gly49 polymorphism in HF, little is known of the effect of this polymorphism in healthy subjects or on the function in response to endogenous agonist (catecholamine) changes. Additionally, there is a lack of research exploring the effect of the Gly49 polymorphism on cardiovascular response to exercise in healthy subjects. This study aimed to identify the effect of $A D R B 1$ polymorphisms on resting cardiovascular function and on cardiovascular response to exercise in healthy subjects.

\section{Materials and Methods}

\section{Subjects}

Data analyzed for this article were part of a larger study on adrenergic receptor genotypes and cardiopulmonary function at rest and during exercise but the data have not been assessed as presented in this study $[18,19]$. This study received approval by the appropriate ethics committee and has therefore been performed in accordance with the ethical standards laid down in the 1964 Declaration of Helsinki and its later amendments. Appropriate consent has been obtained pursuant to law, and the subjects were informed of the benefits and risks of the investigation before signing an institutionally-approved informed consent prior to participation. Seventy-one untrained subjects, ages 20 - 40 years, agreed to participate and were genotyped for Gly49Ser polymorphisms of the $A D R B 1$. All subjects were healthy nonsmokers and not on medication.

\section{Procedures}

Subjects underwent baseline screening tests including pulmonary function testing, an incremental cycle ergometry test to exhaustion on a cycle ergometer, a blood draw for a complete blood count (to rule out anemia) and in women, a pregnancy test. The baseline exercise study, served as an initial familiarization session, was used to determine work intensities for subsequent sessions, and acted as a screening study to rule out myocardial ischemia and abnormal arrhythmias. After these initial tests, subjects met with the Clinical Research Center (CRC) nutritionist and were put on a controlled sodium diet $(3,450 \mathrm{mg} / \mathrm{d})$ for 3 days with a 24 -h urine collection to confirm sodium intake. Subjects subsequently returned to the CRC on two occasions for exercise testing while maintaining a salt neutral diet.

The next session consisted of a cycle ergometry test similar to the first visit but with the additional measurement of Q using a previously validated open-circuit acetylene uptake method [20]. This session served as a further familiarization with the measurements to be made on the final study day and also allowed for confirmation of workloads for the final visit.

On the last study visit, resting measurements of $\mathrm{Q}$, heart rate (HR), stroke volume (SV), and arterial blood pressure (BP) were made. Cardiac output was measured with the open-circuit acetylene method, BP was measured via an arterial catheter, HR was measured via a 3-lead EKG, and SV was calculated by dividing $\mathrm{Q}$ by $\mathrm{HR}$, and cardiac index (CI) was calculated by dividing $\mathrm{Q}$ by weight. Subjects then exercised for $9 \mathrm{~min}$ at about $40 \%$ and 9 min at about $75 \%$ of their peak workload achieved during the initial exercise studies while measurements were repeated every 2 - $3 \mathrm{~min}$. Nine min of exercise was performed because pilot data suggested that this was an adequate time frame to obtain three sets of measures and brought the subjects close to exhaustion with the higher workload with minimal physiologic drift in $\mathrm{VO}_{2}$ and cardiovascular function. All visits were conducted in the morning to account for testing variability.

\section{$A D R B 1$ genotyping}

Buffy coat, obtained from whole blood collected on EDTA, was used for genomic DNA extraction using the Gentra Puregene DNA Isolation Kit (Gentra Systems Inc., Minneapolis, MN, USA), and DNA samples were sent to the University of Arizona Genomics Core for genotype analysis. A polymerase chain reaction (PCR) was conducted according to standard methods, using the following primer sequences (e.g., for Ser49Gly): (forward) 5'-CCG GGC TTC TGG GGT GTT CC-3' and (reverse) 5'-GGC GAG GTG TGG CGA GGT AGC-3', resulting in a $\mathrm{PCR}$ product $564 \mathrm{bps}$ in length. For genotype analysis, a plate of sample DNA was normalized to $1 \mathrm{ng} / \mathrm{uL}$. A total of $10 \mathrm{uL}$ of this stock DNA was plated into an AB1400/W reaction plate (Thermo Fisher) and was vacuum desiccated. A reaction mixture of Taqman Fast Advance Mastermix (Life Technologies), reaction-grade water (Thermo Fisher), and pre-designed Taqman SNP genotyping assays (Life Technologies) was created and pipetted into the wells containing vacuum dried DNA. The plate was sealed with AB1170 Absolute qPCR Plate Seals (Thermo Fisher), centrifuged, and pre-read in an ABI 7300 qPCR instrument. The plates were relocated to a BioRad Tetrad Thermocycler system (BioRad) and reacted. The thermocycling protocol was as follows: one cycle of $15 \mathrm{~min}$ at $45^{\circ} \mathrm{C}, 3 \mathrm{~min}$ at $95^{\circ} \mathrm{C}$, followed by 40 cycles of $15 \mathrm{~s}$ at $95{ }^{\circ} \mathrm{C}$ and $60 \mathrm{~s}$ at $58{ }^{\circ} \mathrm{C}$. The reacted PCR plates were cooled to $4{ }^{\circ} \mathrm{C}$, centrifuged, and post-read on the ABI 7300 instrument. The data were analyzed using the SDS 1.4.1 software. The Ser49Ser homozygous genotype is represented by a single $564 \mathrm{bp}$ band and the Ser49Gly by two products of 219 and $343 \mathrm{bp}$.

\section{Statistical analyses}

All statistical comparisons were made using a statistical software package (SPSS; SPSS Inc, Chicago, IL, USA, version 19). Group demographics were compared with a one-way ANOVA using an $\alpha$ level of 0.05 to determine statistical significance. Genotype differences in performance were compared with an ANOVA to detect differences among the specific geno- 
type groups.

\section{Results}

\section{Subject characteristics}

Seventy-one subjects were enrolled in this study (36 male and 35 female). Genotyping for $A D R B 1$ was completed for amino acid position 49 with individuals who were homozygous for serine (Ser49Ser, $\mathrm{n}=52$ ) or heterozygous (Gly49Ser, $\mathrm{n}=19$ ) at codon 49. There was no statistically significant difference between genotype groups for age, height, weight, body mass index (BMI), or peak watts achieved, during the maximal exercise test (Table 1).

\section{Cardiac output, stroke volume and blood pressure}

There were no statistically significant differences between genotype groups for cardiac output (Q) or systolic blood pressure $\left(\mathrm{BP}_{\text {sys }}\right)$ at rest, peak exercise, or in change from rest to peak exercise (Fig. 1). There were no significant differences between genotype groups for diastolic blood pressure $\left(\mathrm{BP}_{\text {dias }}\right)$ or stroke volume (SV) at rest or peak exercise (Fig. 1). There was a trend towards significance between genotype groups for change in $\mathrm{SV}(\mathrm{P}=0.058)$ from rest to peak exercise. Furthermore, while not statistically significant $(\mathrm{P}=0.08)$, there was a clinically significant difference between genotype groups for change in $\mathrm{BP}_{\text {dias }}$ from rest to peak exercise $(-5.5 \pm 15.4$ and $1.3 \pm 11.5 \mathrm{~mm} \mathrm{Hg}$ for Ser49Ser and Gly49Ser respectively) (Fig. 1). We have defined this as clinically significant as small changes in BP (about $5 \mathrm{~mm} \mathrm{Hg}$ ) can drastically influence survival in HF patients [21].

\section{Cardiac index, heart rate and systemic vascular resistance}

There were no statistically significant differences between genotype groups for $\mathrm{CI}$ at peak exercise or for change in $\mathrm{CI}$ from rest to peak exercise. Nor were there any differences between genotype groups for resting HR or for change in HR from rest to peak exercise. Further, there were no statistically significant differences between genotype groups in systemic vascular resistance (SVR) at peak exercise or for change in SVR from rest to peak exercise. There were, however, differences between genotype groups for resting $\mathrm{CI}(\mathrm{P}=0.037)$ and $\operatorname{SVR}(\mathrm{P}=0.046)$ and for $\mathrm{HR}$ at peak exercise $\left(\mathrm{HR}_{\max }\right)(\mathrm{P}=$ 0.016), with the Gly49Ser genotype presenting improved CI and a lower SVR at rest, and a higher HR at peak exercise (Fig. 2).

\section{Discussion}

In the present study, we demonstrate that genetic variation of the $A D R B 1$ is associated with differences in some components of the cardiovascular responses to peak exercise in healthy
Table 1. Subject Characteristics

\begin{tabular}{|c|c|c|c|}
\hline Study demographics & No. & Mean \pm SD & P-value \\
\hline \multicolumn{4}{|l|}{ Sex (Male/female) } \\
\hline Ser49Ser & $26 / 26$ & - & - \\
\hline Gly49Ser & $10 / 9$ & - & - \\
\hline Total & $36 / 35$ & - & - \\
\hline \multicolumn{4}{|l|}{ Age (yrs) } \\
\hline Ser49Ser & 52 & $28.9 \pm 5.6$ & 0.25 \\
\hline Gly49Ser & 19 & $30.6 \pm 6.4$ & \\
\hline Total & 71 & $29.3 \pm 5.8$ & \\
\hline \multicolumn{4}{|l|}{ Height (cm) } \\
\hline Ser49Ser & 52 & $173.6 \pm 9.9$ & 0.87 \\
\hline Gly49Ser & 19 & $174 \pm 7.4$ & \\
\hline Total & 71 & $173.7 \pm 9.3$ & \\
\hline \multicolumn{4}{|l|}{ Weight (kg) } \\
\hline Ser49Ser & 52 & $74.4 \pm 13.3$ & 0.5 \\
\hline Gly49Ser & 19 & $71.9 \pm 13.5$ & \\
\hline Total & 71 & $73.8 \pm 13.3$ & \\
\hline \multicolumn{4}{|l|}{ BMI } \\
\hline Ser49Ser & 52 & $24.6 \pm 3.5$ & 0.33 \\
\hline Gly49Ser & 19 & $23.6 \pm 3.3$ & \\
\hline Total & 71 & $24.3 \pm 3.4$ & \\
\hline \multicolumn{4}{|l|}{ Watts } \\
\hline Ser49Ser & 52 & $223.8 \pm 76.8$ & 0.33 \\
\hline Gly49Ser & 19 & $205 \pm 49.4$ & \\
\hline Total & 71 & $218.7 \pm 70.6$ & \\
\hline
\end{tabular}

Ser49Ser: genotype (homozygous for $A D R B 1$ resulting in serine at amino acid 49); Gly49Ser: genotype (heterozygous for $A D R B 1$ resulting in one glycine and one serine at amino acid 49); BMI: body mass index. There were no statistically significant differences in demographic data.

subjects. Individuals with one glycine allele (Gly49Ser) at amino acid 49 demonstrate a trend towards significance for change in SV from rest to peak exercise. The Gly49Ser polymorphism demonstrated a blunted response in SV in response to peak exercise and a significant change in $\mathrm{BP}_{\text {dias }}$ from rest to peak exercise, and the Gly49Ser polymorphism demonstrated a greater increase in $\mathrm{BP}_{\text {dias }}$ and the Ser49Ser polymorphism demonstrating a decrease in $\mathrm{BP}_{\text {dias }}$. Further, the Gly49Ser polymorphism demonstrated an improved CI at rest, an increased $\mathrm{HR}_{\max }$ at peak exercise, and a lower SVR at rest compared to the Ser49Ser polymorphism.

The ADRB1 subtype is found primarily in the heart and comprises $75-80 \%$ of total $\beta$-AR found in the heart and approximately $95 \%$ of $\beta$-AR in the SA node [22]. The G protein signaling pathway associated with the $\beta$-AR is important in the modulation of several key target proteins. When activated, cardiomyocyte ADRB1 preferentially binds to the $\mathrm{G}_{\mathrm{as}}$ protein which phosphorylates AC, generating the secondary messenger cAMP. Increased cAMP accumulation activates PKA [23]. 

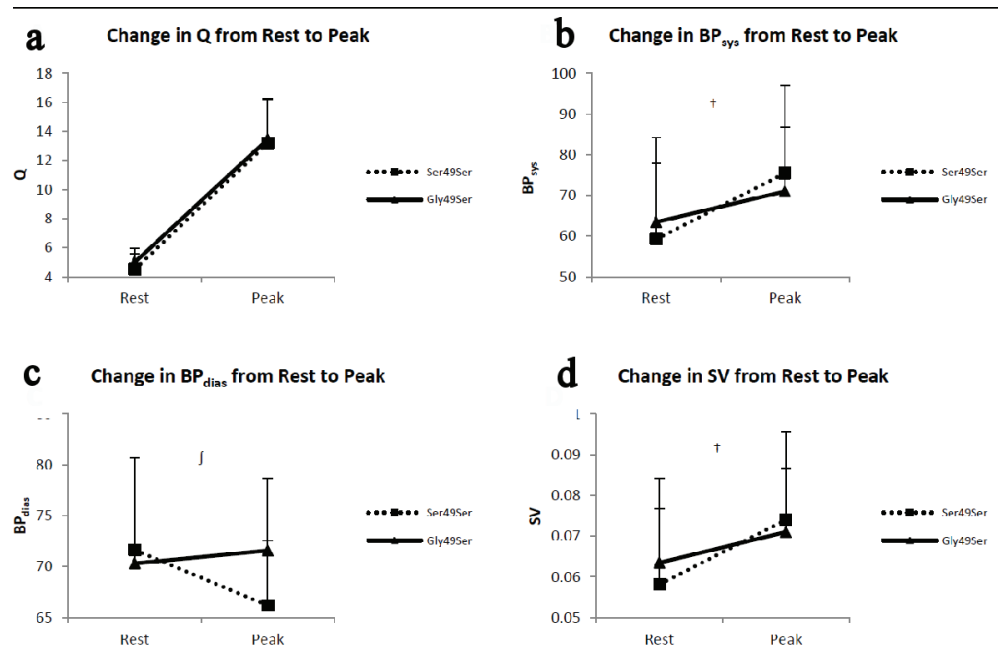

Figure 1. Panels depict the change from rest to peak exercise in (a) cardiac output $(\mathrm{Q})$, (b) systolic blood pressure $\left(B P_{\text {sys }}\right),(c)$ diastolic blood pressure $\left(\mathrm{BP}_{\text {dias }}\right)$, and (d) stroke volume (SV). The error bars represent the SE of the mean. †Possible trend towards significance for change in $\mathrm{BP}_{\text {sys }}(P=0.08)$ and SV $(P=0.058)$ from rest to peak between genotype groups. JClinically significant difference between genotype groups for change in $\mathrm{BP}_{\text {dias }}$ from rest to peak exercise $(-5.5 \pm 15.4$ and $1.3 \pm 11.5$ for Ser49Ser and Gly49Ser, respectively).

Activated PKA then phosphorylates troponin I, the L-type $\mathrm{Ca}^{2+}$ channel and phospholamban (PLB), increasing cardiac inotropy, chronotropy and lusitropy [24].

Research has also shown $\mathrm{G}_{\mathrm{s}}$ activation can increase L-type $\mathrm{Ca}^{2+}$ current directly [8]. L-type $\mathrm{Ca}^{2+}$ channels play an integral role in cardiomyocyte excitability and contractility [1]. Phosphorylation of cardiac L-type $\mathrm{Ca}^{2+}$ channels by PKA results in an influx of $\mathrm{Ca}^{2+}$ into cardiomyocytes. The $\mathrm{Ca}^{2+}$ then binds to the sarco/endoplasmic reticulum $\mathrm{Ca}^{2+}$-ATPase (SERCA) triggering further sarcoplasmic $\mathrm{Ca}^{2+}$ loading resulting in the removal of troponin and tropomyosin inhibition of myosin binding sites $[25,26]$. Additionally, the phosphorylation of phospholamban (PLB) via PKA, a downstream protein from
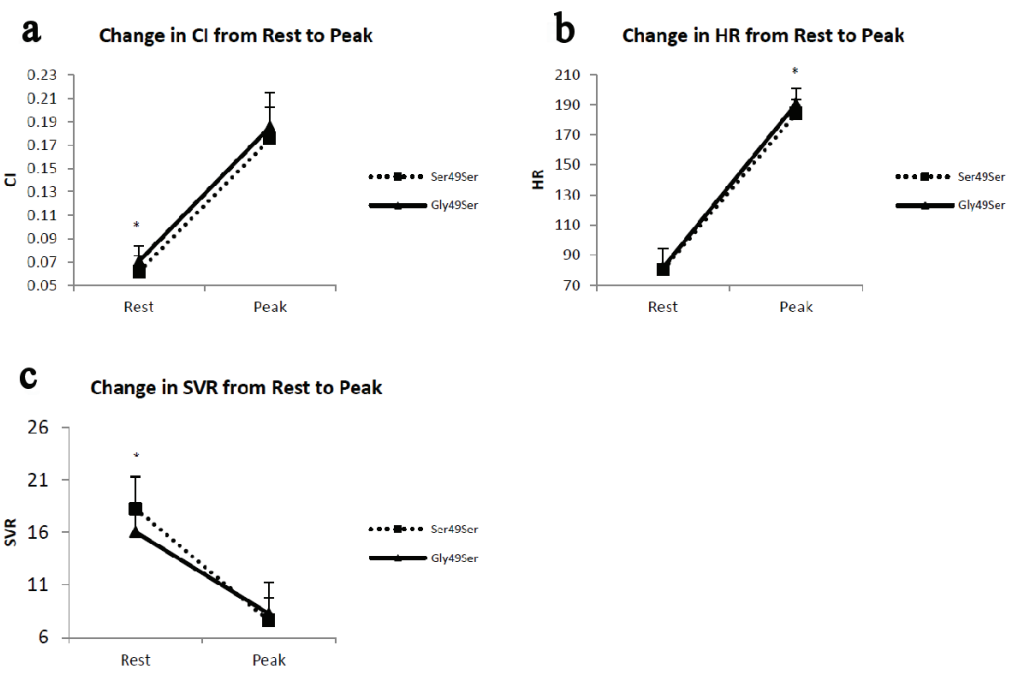

$\beta$-AR stimulation, has been shown to result in the removal of inhibition of SERCA. This increases the quantity and rate of reuptake of cytosolic calcium in the sarcoplasmic reticulum [27]. Recent research also suggests PLB is not sequestered only to the sarcoplasmic reticulum but, rather, PLB pools exist in the nuclear envelope which allows them to regulate perinuclear/nuclear calcium handling [28]. Troponin I is a regulatory protein of cardiac myofibrils and its phosphorylation by PKA inhibits actomyosin ATPase activity resulting in relaxation of cardiomyocytes in response to catecholamines $[12,29]$.

Genetic variants of the ADRBI have been shown to modulate the cardiac responses to catecholamine binding; the Gly49 polymorphism has been shown to produce a dampening effect

Figure 2. Panels depict the change from rest to peak exercise in (a) cardiac index (Cl), (b) heart rate (HR) and (c) systemic vascular resistance (SVR). The error bars represent the SE of the means. ${ }^{*} P<0.05$ for Ser49Ser vs. Gly49Ser pairwise comparisons. 
to these responses. These data suggest genetic variations of the $A D R B 1$ may influence cardiovascular responses to exercise in healthy subjects. In the present study, subjects with the Gly49Ser polymorphism present with a statistically significantly improved cardiac index as compared to the Ser49Ser polymorphism at rest; this difference is abolished at peak exercise. This suggests improved cardiac function at rest with no deleterious effect on cardiac function at peak exercise. Additionally, there is a statistically significant difference between the two polymorphisms for $\mathrm{HR}_{\max }$ and no difference at rest, with the Gly49Ser polymorphism demonstrating a higher $\mathrm{HR}_{\max }$. This suggests the Gly49Ser polymorphism has an improved HR reserve. Further, this polymorphism (Gly49Ser) also demonstrated a lower SVR at rest, suggesting the Gly49Ser polymorphism has decreased cardiac work at rest. This coupled with the abolishment of this difference at peak exercise suggests subjects with the Gly49Ser polymorphism have an improved cardiac work reserve. Furthermore, the trend towards significance in change in stroke volume from rest to peak exercise, with the Gly49Ser polymorphism presenting a dampened increase, in addition to there being no difference in HR at rest and improved CI at rest, suggests an improved left ventricular contractility in the Gly49Ser polymorphism. It is interesting to note the clinically significant difference between genotype groups in change in $\mathrm{BP}_{\text {dias }}$ rest to peak exercise may suggest a systemic influence of the $A D R B 1$ genotype, particularly in the typically observed arterial vasodilation observed in response to aerobic exercise. These data suggest the Gly49Ser polymorphism to have improved cardiovascular function at rest and peak exercise.

ADRB1 signalling has been shown to play an important role in HF with the degree of sympathetic activity being inversely correlated with survival [30]. Deleterious effects of ADRB1 signalling include apoptosis, myocyte growth, fibroblast hyperplasia, myopathy, fetal gene induction and proarrhythmia [31,32]. As an adaptive mechanism in HF, cardiac ADRB1s become less responsive, either downregulating or uncoupling from the $G_{\mathrm{s}}$ pathway [33]. This suggests the less functional variant of the ADRB1 to be clinically important in $\mathrm{HF}$ and our data confirm that further study is certainly warranted.

The present study did not demonstrate as large of an effect of $A D R B 1$ polymorphisms on cardiovascular parameters in healthy subjects as the current research has demonstrated in HF. We postulate this may be due to the change in $\beta$-AR ratios in $\mathrm{HF}$ and epinephrine/norepinephrine binding affinities for ADRB1 and ADRB2. Previous work has demonstrated a decrease in cardiomyocyte ADRB1 concentration by as much as $61 \%$ in HF with no or little corresponding decrease in ADRB2 concentrations [33-36]. Furthermore, ADRB1 receptors have a high binding affinity for both epinephrine and norepinephrine while ADBR2 receptors have a high binding affinity for epinephrine and a low binding affinity for norepinephrine [37]. Additionally, there is little to no ADRB1 receptor reserve for positive cardiovascular ionotropic effects $[9,38,39]$. This decrease in $\beta$-AR concentration, particularly ADRB1 concentration, and successive decreased catecholamine sensitivity coupled with a low ADRB1 reserve, suggests this decrease in ADRB1 receptor concentrations is a protective mechanism in HF and modulates the effect of ADRB1 polymorphisms on cardiovascular parameters.

Current research suggests a cardioprotective effect of the Gly49 polymorphism in HF and other cardiac pathologies. This present study supports this notion, suggesting improved cardiovascular function at rest and response to peak exercise in healthy subjects and supporting the use of beta-blockers to improve exercise tolerance in HF patients. These findings may be clinically important as exercise is an essential aspect of cardiac rehabilitation following cardiac exacerbations. The ability to improve exercise tolerance in this population may prove integral in improving the efficacy and adherence to exercise as a part of cardiac rehabilitation.

\section{Limitations}

There are inherent limitations regarding genetics studies including sample size and genotype distribution. Limited statistical power because of the modest sample size and different genotype distribution in the present study $(\mathrm{n}=71)$ may have played a role in limiting the significance of some of the statistical comparisons conducted. A post hoc power analysis revealed the power to detect statistically significant differences between groups for CI at rest and $\mathrm{HR}_{\max }$ to be 0.625 and 0.613 , respectively at $\alpha=0.05$, suggesting sufficient sample size for the present study. Furthermore, our study population was void of the homozygous Gly49Gly genotype. This can be explained by the genotype frequency of the three genotypes present at amino acid $49(0.69,0.29$, and 0.04 for Ser49Ser, Gly49Ser, and Gly49Gly respectively) but may vary among different racial/ethnic groups [40]. However, present research has demonstrated the Gly49Ser and Gly49Gly polymorphisms function similarly, suggesting there is no additive effect of an additional glycine present at amino acid 49 and that the Gly49Ser polymorphism may be representative of the Gly49 polymorphism as a whole for $A D R B 1[9,11]$.

\section{Conclusions}

The present study examined the influence of $A D R B 1$ genotype on cardiovascular response to exercise in healthy subjects. Our data demonstrated the Gly49Ser genotype has a blunted SV response to peak exercise and a significant change in $\mathrm{BP}_{\text {dias }}$ from rest to peak exercise compared to the Ser49Ser genotype. Additionally, the Gly49Ser demonstrated improved CI at rest, increased $\mathrm{HR}_{\text {max }}$ at peak exercise, and a lower SVR at rest compared to the Ser49Ser genotype. The current study suggests improved cardiovascular function at rest and response to peak exercise in healthy subjects and provides further evidence to the cardioprotective effect of the Gly 49 polymorphism in a healthy population.

\section{Conflict of Interest}

All authors declare they have no conflict of interest. 


\section{Grant Support}

This study was funded by National Institute of Health (NIH) grants: HL108962-06.

\section{References}

1. Vassilatis DK, Hohmann JG, Zeng H, Li F, Ranchalis JE, Mortrud MT, Brown A, et al. The G protein-coupled receptor repertoires of human and mouse. Proc Natl Acad Sci U S A. 2003;100(8):4903-4908.

2. Xiao RP. Beta-adrenergic signaling in the heart: dual coupling of the beta2-adrenergic receptor to $G(s)$ and $G(i)$ proteins. Sci STKE. 2001;2001(104):re15.

3. Berdeaux R, Goebel N, Banaszynski L, Takemori H, Wandless T, Shelton GD, Montminy M. SIK1 is a class II HDAC kinase that promotes survival of skeletal myocytes. Nat Med. 2007;13(5):597-603.

4. Carlezon WA, Jr., Duman RS, Nestler EJ. The many faces of CREB. Trends Neurosci. 2005;28(8):436-445.

5. Lee SJ, McPherron AC. Regulation of myostatin activity and muscle growth. Proc Natl Acad Sci U S A. 2001;98(16):9306-9311.

6. Mayr B, Montminy M. Transcriptional regulation by the phosphorylation-dependent factor CREB. Nat Rev Mol Cell Biol. 2001;2(8):599-609.

7. Ruas JL, White JP, Rao RR, Kleiner S, Brannan KT, Harrison BC, Greene NP, et al. A PGC-1alpha isoform induced by resistance training regulates skeletal muscle hypertrophy. Cell. 2012;151(6):1319-1331.

8. Ladage D, Schwinger RH, Brixius K. Cardio-selective beta-blocker: pharmacological evidence and their influence on exercise capacity. Cardiovasc Ther. 2013;31(2):76-83.

9. Brodde OE. Beta 1- and beta 2-adrenoceptors in the human heart: properties, function, and alterations in chronic heart failure. Pharmacol Rev. 1991;43(2):203-242.

10. Borjesson M, Magnusson Y, Hjalmarson A, Andersson B. A novel polymorphism in the gene coding for the beta(1)adrenergic receptor associated with survival in patients with heart failure. Eur Heart J. 2000;21(22):1853-1858.

11. Brodde OE. Beta-1 and beta-2 adrenoceptor polymorphisms: functional importance, impact on cardiovascular diseases and drug responses. Pharmacol Ther. 2008;117(1):1-29.

12. Levin MC, Marullo S, Muntaner O, Andersson B, Magnusson Y. The myocardium-protective Gly-49 variant of the beta 1-adrenergic receptor exhibits constitutive activity and increased desensitization and down-regulation. J Biol Chem. 2002;277(34):30429-30435.

13. Rathz DA, Brown KM, Kramer LA, Liggett SB. Amino acid 49 polymorphisms of the human beta1-adrenergic receptor affect agonist-promoted trafficking. J Cardiovasc Pharmacol. 2002;39(2):155-160.

14. Flather MD, Shibata MC, Coats AJ, Van Veldhuisen DJ, Parkhomenko A, Borbola J, Cohen-Solal A, et al. Randomized trial to determine the effect of nebivolol on mortality and cardiovascular hospital admission in el- derly patients with heart failure (SENIORS). Eur Heart J. 2005;26(3):215-225.

15. Groenning BA, Nilsson JC, Sondergaard L, Fritz-Hansen T, Larsson HB, Hildebrandt PR. Antiremodeling effects on the left ventricle during beta-blockade with metoprolol in the treatment of chronic heart failure. J Am Coll Cardiol. 2000;36(7):2072-2080.

16. Hall SA, Cigarroa CG, Marcoux L, Risser RC, Grayburn PA, Eichhorn EJ. Time course of improvement in left ventricular function, mass and geometry in patients with congestive heart failure treated with beta-adrenergic blockade. J Am Coll Cardiol. 1995;25(5):1154-1161.

17. Nagatomo Y, McNamara DM, Alexis JD, Cooper LT, Dec GW, Pauly DF, Sheppard R, et al. Myocardial Recovery in Patients With Systolic Heart Failure and Autoantibodies Against beta1-Adrenergic Receptors. J Am Coll Cardiol. 2017;69(8):968-977.

18. Kelley EF, Johnson BD, Snyder EM. Beta-2 Adrenergic Receptor Genotype Influences Power Output in Healthy Subjects. J Strength Cond Res. 2017;31(8):2053-2059.

19. Snyder EM, Beck KC, Dietz NM, Eisenach JH, Joyner MJ, Turner ST, Johnson BD. Arg16Gly polymorphism of the beta2-adrenergic receptor is associated with differences in cardiovascular function at rest and during exercise in humans. J Physiol. 2006;571(Pt 1):121-130.

20. Johnson BD, Beck KC, Proctor DN, Miller J, Dietz NM, Joyner MJ. Cardiac output during exercise by the open circuit acetylene washin method: comparison with direct Fick. J Appl Physiol (1985). 2000;88(5):1650-1658.

21. Hopkins AL, Lamm MG, Funk JL, Ritenbaugh C. Hibiscus sabdariffa L. in the treatment of hypertension and hyperlipidemia: a comprehensive review of animal and human studies. Fitoterapia. 2013;85:84-94.

22. Madamanchi A. Beta-adrenergic receptor signaling in cardiac function and heart failure. Mcgill J Med. 2007;10(2):99-104.

23. Freedman NJ, Lefkowitz RJ. Anti-beta(1)-adrenergic receptor antibodies and heart failure: causation, not just correlation. J Clin Invest. 2004;113(10):1379-1382.

24. Lohse MJ, Engelhardt S, Eschenhagen T. What is the role of beta-adrenergic signaling in heart failure? Circ Res. 2003;93(10):896-906.

25. Kamp TJ, Hell JW. Regulation of cardiac L-type calcium channels by protein kinase $\mathrm{A}$ and protein kinase C. Circ Res. 2000;87(12):1095-1102.

26. Doran P, Dowling P, Donoghue P, Buffini M, Ohlendieck $\mathrm{K}$. Reduced expression of regucalcin in young and aged mdx diaphragm indicates abnormal cytosolic calcium handling in dystrophin-deficient muscle. Biochim Biophys Acta. 2006;1764(4):773-785.

27. Haghighi K, Gregory KN, Kranias EG. Sarcoplasmic reticulum Ca-ATPase-phospholamban interactions and dilated cardiomyopathy. Biochem Biophys Res Commun. 2004;322(4):1214-1222.

28. Wu AZ, Xu D, Yang N, Lin SF, Chen PS, Cala SE, Chen Z. Phospholamban is concentrated in the nuclear envelope of cardiomyocytes and involved in perinuclear/nuclear calcium handling. J Mol Cell Cardiol. 2016;100:1-8.

29. Kaumann A, Bartel S, Molenaar P, Sanders L, Burrell K, 
Vetter D, Hempel P, et al. Activation of beta2-adrenergic receptors hastens relaxation and mediates phosphorylation of phospholamban, troponin I, and C-protein in ventricular myocardium from patients with terminal heart failure. Circulation. 1999;99(1):65-72.

30. Packer M. Neurohormonal interactions and adaptations in congestive heart failure. Circulation. 1988;77(4):721730 .

31. Mann DL, Kent RL, Parsons B, Cooper Gt. Adrenergic effects on the biology of the adult mammalian cardiocyte. Circulation. 1992;85(2):790-804.

32. Communal C, Singh K, Sawyer DB, Colucci WS. Opposing effects of beta(1)- and beta(2)-adrenergic receptors on cardiac myocyte apoptosis : role of a pertussis toxin-sensitive G protein. Circulation. 1999;100(22):2210-2212.

33. Bristow MR, Ginsburg R, Minobe W, Cubicciotti RS, Sageman WS, Lurie K, Billingham ME, et al. Decreased catecholamine sensitivity and beta-adrenergicreceptor density in failing human hearts. N Engl J Med. 1982;307(4):205-211.

34. Fowler MB, Laser JA, Hopkins GL, Minobe W, Bristow MR. Assessment of the beta-adrenergic receptor pathway in the intact failing human heart: progressive receptor down-regulation and subsensitivity to agonist response.
Circulation. 1986;74(6):1290-1302.

35. Ungerer M, Bohm M, Elce JS, Erdmann E, Lohse MJ. Altered expression of beta-adrenergic receptor kinase and beta 1-adrenergic receptors in the failing human heart. Circulation. 1993;87(2):454-463.

36. Bristow MR, Hershberger RE, Port JD, Minobe W, Rasmussen R. Beta 1- and beta 2-adrenergic receptor-mediated adenylate cyclase stimulation in nonfailing and failing human ventricular myocardium. Mol Pharmacol. 1989;35(3):295-303.

37. Molinoff PB. Alpha- and beta-adrenergic receptor subtypes properties, distribution and regulation. Drugs. 1984;28(Suppl 2):1-15.

38. Port J, Bristow M. Lack of spare beta-adrenergic receptors in the human-heart. Faseb Journal; 1988: Federation Amer SOC EXP Biol 9650 Rockville Pike, Bethesda, MD 20814-3998.

39. Snyder EM, Johnson BD, Joyner MJ. Genetics of beta2adrenergic receptors and the cardiopulmonary response to exercise. Exerc Sport Sci Rev. 2008;36(2):98-105.

40. Genomes Project C, Abecasis GR, Auton A, Brooks LD, DePristo MA, Durbin RM, Handsaker RE, et al. An integrated map of genetic variation from 1,092 human genomes. Nature. 2012;491(7422):56-65. 